\title{
CARTOGRAFIA DE CINEMA EM RIO DOCE/CDU
}

\author{
Maria Helena Braga e Vaz da Costa \\ Universidade Federal do Rio Grande do Norte - UFRN \\ Curso de Artes Visuais \\ Grupo de Pesquisa Linguagens da Cena: Imagem, Cultura e Representação \\ mhcosta.ufrn@gmail.com
}

\begin{abstract}
RESUMO
Este artigo apresenta uma discussão sobre as capacidades espaciais e cartográficas das imagens cinematográficas, particularmente as produzidas pelo cinema pernambucano contemporâneo. Discutindo sobre uma "cartografia cinematográfica", que permite a compreensão e a análise crítica de uma representação cinematográfica espacial específica, este artigo analisa a cartografia cinematográfica construída pelo documentário do filme Rio Doce / CDU (2013), escrito e dirigido por Adelina Pontual. Por meio da análise do discurso fílmico, chegou-se à conclusão de que a geografia que se materializa a partir desse filme é uma geografia da representação da experiência espacial produzida e vivenciada por um tipo de cartografia que se constitui a partir de ambas existências: real e fílmica.
\end{abstract}

Palavras-chave: Cartografia. Cinema. Rio Doce/CDU.

\section{CINEMATIC CARTOGRAPHY IN RIO DOCE/CDU}

\begin{abstract}
This paper presents a discussion about the spatial and cartographic capabilities of the film images, particularly the ones produced by Pernambuco's contemporary cinema. Discussing about a "cinematic cartography" that allows for an understanding, and a critical analises, of an specific urban space film representation, this paper analyses the cinematic cartography build by the film documentary Rio Doce/CDU (2013), writen and directed by Adelina Pontual. By means of analysis of film discourse it is conclude that this film materializes a geography of the representations of spatial experience which is produced and experienced by a kind of cartography constituted by real and film existence.
\end{abstract}

Keywords: Cartography. Cinema. Rio Doce/CDU.

\section{INTRODUÇÃO}

A ideia de que filme pode funcionar como um mapa não é em si mesma uma novidade haja vista a fascinação de Walter Benjamin pela possibilidade da produção de um mapa cinematográfico de Paris. O que representa atualmente uma novidade significante, no que toca o que podemos nomear como "cartografia cinematográfica, é que, com o desenvolvimento das propriedades de localização contidas na imagem em movimento e o processo de "navegação" espacial e temporal, cresceu o interesse no estudo relacionado às possibilidades que entram em jogo a partir de investigações sobre as imagens cinematográficas no âmbito histórico, geográfico, urbano e arquitetônico (PASSOS e KASTRUP, 2009).

Uma cartografia cinematográfica, assim, serve ao estudo do mapeamento das práticas e perspectivas críticas que informam sobre a relação entre o espaço, o lugar e a cultura visual; a cultura da imagem em movimento que proporciona a visualização do movimento das pessoas e dos objetos no espaço. Se um mapa representa uma totalidade espacial, uma vez que os 
cineastas editam diferentes cenas/tomadas de uma cidade, e de sua arquitetura, onde se desenvolve a ação, por exemplo, a ideia de cartografia cinematográfica se configura como uma proposição de reorientação e reorganização do espaço, urbano ou não, produzindo, consequentemente, a demolição e a reconstrução da imagem da cidade objeto da construção imagética. Portanto, difere-se então a cidade como espaço de "locação" daquela que compõe o filme e é efetivamente visualizada pelo espectador.

Esse trabalho propõe uma reflexão sobre a intrínseca capacidade espacial e cartográfica das imagens fílmicas, mais particularmente as construídas pelo cinema contemporâneo produzido em Pernambuco, no sentido de discutir sobre uma cartografia cinematográfica que permite 0 entendimento e a análise crítica sobre o olhar constituído a partir da representação imagética de determinado espaço urbano. Pretende-se, ainda, responder neste trabalho a questões do tipo: em que termos imagens fílmicas evoluem em mapas e cartografias? Em que sentido nosso conhecimento e entendimento dos espaços apontam para um tipo de cognição através das imagens fílmicas?

Em vista do exposto, discute-se aqui sobre a cartografia cinematográfica construída no filme/documentário pernambucano Rio Doce/CDU (2013), roteirizado e dirigido por Adelina Pontual. Parte-se, nesse caso, da análise das imagens em movimento do e no espaço urbano de duas cidades pernambucanas: Olinda e Recife, aqui consideradas no âmbito de uma "cartografia moderna" através da qual o espaço urbano filmado e projetado (no sentido cinemático e geográfico) está envolto em uma moldura cultural de percepção do espaço que possibilita novos entendimentos sobre o lugar como espaço vivido e imaginado.

Considerar o entrecruzamento das imagens dessas duas cidades no filme, por meio da análise crítica do discurso a partir de uma "cartografia cinemática", que evidentemente é construída culturalmente, nos parece primordial para estabelecer parâmetros de entendimento da relação posta entre as imagens em movimento do espaço urbano, a experiência humana de deslocamento no espaço, e a imagificação (filme) dessa experiência espacial produzida e vivenciada nas cidades que conhecemos em ambas existências: real e fílmica.

\section{Rio Doce/CDU como Cartografia Cinemática do Lugar}

Normalmente, nos textos atuais, quando há menção à "cartografia de cinema", a referência diz respeito a mapas introdutórios que focam na ideia de "cartografar" (no tempo) as produções e representações fílmicas no contexto de determinados tipos, gêneros, nacionalidades, etc. em suas manifestações cinematográficas (SUPPIA, 2013; 2017). Isto é, diz respeito a fazer uso de uma abordagem consagrada, que é a do mapeamento dentro de um contexto específico, a fim de expandir o cânone, revisitar e revisar a história da produção cinematográfica. Para efeito desse trabalho, no entanto, essa não é a referência utilizada.

O substantivo feminino cartografia tem como definição: conjunto de estudos e operações científicas, técnicas e artísticas que orienta os trabalhos de elaboração de cartas geográficas. Por sua vez, o adjetivo cinematográfico corresponde ao que é próprio do cinema e da ilusão óptica do movimento. Assim, a análise de uma cartografia cinematográfica, proposta nesse trabalho, se dará a partir do entendimento de que filme, resultante de operações técnicas e artísticas, pode ser estudado como uma carta geográfica" de um determinando espaço geográfico, que é elaborada assumindo uma condição cinemática; isto é: por meio da composição, em movimento (ou a impressão visual de movimento), de imagens dos corpos e dos objetos que se apresentam no espaço.

Pensar as imagens fílmicas como partes de uma cartografia construída pelo aparato cinematográfico implica em considerar as imagens que compõem o filme como constructos da representação que se articulam, de maneira cinemática, para gerar um "mapa" imagético que dá conta de um espaço (urbano, no caso) específico. Elementos intrínsecos ao aparato cinematográfico como posicionamento e angulação da câmera; edição e composição das imagens e dos sons, e o trabalho de montagem e construção narrativa servem como instrumentos para a estruturação de uma geografia fílmica que advém da forma cinemática (COSTA, 2011). 
Para Deleuze e Guattari (1995) o sentido de cartografia diz respeito ao "acompanhamento de percursos, implicação em processos de produção, conexão de redes ou rizomas" (p.10). A palavra "rizoma", que deriva da referência à morfologia botânica, é utilizada como modelo descritivo ou epstemológico por Deleuze e Guattari no desenvolvimento de sua teoria filosófica significando: um sistema epstemológico em que não há uma base sólida que legitima ou autoriza alguma coisa; ou seja, em que não há proposições ou afirmações mais fundamentais do que outras. Assim,

Cartografia surge como um princípio do rizoma [...] A realidade cartografada se apresenta como um mapa móvel, de tal maneira que tudo aquilo que tem aparência de "o mesmo" não passa de um concentrado de significação, de saber e de poder, que pode por vezes ter a pretensão ilegítima de ser centro de organização do rizoma. (DELEUZE; GUATTARI,1995, p.10)

Nesse sentido, filme, enquanto "realidade cartografada", é um "mapa móvel" através do qual percorremos espaços e lugares que podem, ou não, nos parecer familiar. Parafraseando Deleuze e Guattari, a realidade cartografada que nos é apresentada, com toda a verossimilhança que tenha em relação a sua contrapartida no que denominamos de realidade, adquire significação no processo de produção do próprio mapa. Esse mapa, logicamente, resulta de uma maneira de olhar, pensar e entender o espaço/lugar imagetificado e, portanto, o filme é uma cartografia de uma ideia, uma intenção, um olhar, um posicionamento específico sobre o, e no espaço cartografado. Podemos, então, considerar esse mapa móvel como uma cartografia do significado que associamos ao espaço/lugar.

Em acordo, podemos instituir que filme pode ser considerado como um documento cartográfico. Nesse sentido, o que ele mapeia? Que tipo de "geografia" se materializa por meio dessa cartografia? Para fins desse trabalho mais especificamente, as respostas a essas perguntas serão apresentadas no que se refere à cartografia cinemática construída e estabelecida no filme Rio Doce/CDU.

Rio Doce/CDU apresenta uma viagem de ônibus através das cidades de Olinda e Recife seguindo a trajetória da Linha 920 - Rio Doce/CDU. Em seu trajeto, o ônibus sai do Terminal de Integração de Rio Doce (4ํㅡㄹ periferia do Recife - Pau Amarelo, Mamanguape; Encruzilhada; Campo Grande; Engenho do Meio; Cidade Universitária - percorrendo longas avenidas como a Av. Agamenon Magalhães e a Av. Caxangá. Adelina Pontual classificou seu filme como um "exercício voyeurístico" que intenciona captar a atmosfera suburbana dessas duas cidades. E é exatamente essa atmosfera suburbana que a cineasta coloca no centro dessa cartografia cinemática traçada e revelada a partir das imagens da paisagem urbana de Olinda e Recife onde uma diversidade de tipos humanos que habitam, trabalham e se deslocam como usuários da Linha 920 aparecem como protagonistas.

O "exercício voyeurístico" executado por Pontual se materializa através das imagens originadas pelo deslocamento do ônibus que se mostram enquanto "imagens de percurso" captadas durante a "viagem" que se materializa nesse percurso geográfico-fílmico cortando diversos bairros das cidades de Olinda e Recife e revelando a paisagem urbana em sua diversidade imagética e (sub)urbana.

Destaca-se durante o filme a insistência de captar/mostrar a paisagem como reflexo, isto é, as imagens da paisagem urbana são apresentadas a partir de como estas refletem nas janelas do ônibus, literalmente sendo vistas, por nós espectadores, como imagens espelhadas do espaço urbano percorrido e compostas pelo fluxo de pessoas nas ruas, carros, a arquitetura dos bairros, a diversidade de casas e edifícios, o comércio. Interessante notar também que os sons, ruídos e odores que advém das ruas por onde se desloca o ônibus, materializam uma realidade urbana que se dá no percurso por meio da aproximação das imagens espelhadas, das imagens reflexos, distanciadas pelo formato do "exercício voyeurístico" seguido por Pontual.

Intercalando imagens em movimento no e do ônibus, com as entrevistas com pessoas que utilizam, ou utilizaram por muito tempo, o transporte público, e mais especificamente a Linha Rio Doce/CDU diariamente, Adelina Pontual constrói uma cartografia cinemática que agrega valor humano à geografia fílmica que nos é apresentada. No início do filme, por exemplo, ouvimos em off que a experiência de andar no ônibus da Linha 920 se assemelha a um "percurso turístico". "Quem quer conhecer a cidade, pegue ele"; isto é, o espaço da cidade, na 
opinião desse usuário, se mostra em sua totalidade nessa experiência de transporte proporcionada pela Linha Rio Doce/CDU.

Ademais, depoimentos emotivos sobre a experiência de uso da Linha 920 só intensificam a noção de valor humano agregado a uma maneira de ver e experienciar a cidade (o espaço urbano) de uma forma específica (dentro do ônibus em movimento) e através de uma geografia específica (o percurso imposto pela trajetória do ônibus) que são então compostas e apresentadas pelo filme, este último, e este é meu argumento, construído e apresentado como uma cartografia cinemática. Depoimentos como o que ouvimos de uma moça na Feira do Rio Doce, ainda no KM 2 do percurso, ou o de uma mulher que trabalha numa loja na Avenida Caxangá, KM 22 já próximo ao fim do percurso, respectivamente, servem como ótimos exemplos:

Fiz a minha graduação inteira lá na Federal e o mestrado também, andando de ônibus. Então eu pegava um ônibus do Janga pra Olinda, e eu ainda pegava aquele Rio Doce/CDU, que todo mundo conhece muito bem, que sempre tá muito lotado, nunca tem lugar para sentar, às vezes nem em pé também, né? Dependendo do horário. E aí foram muitos anos assim, indo e voltando.

Muitos anos, sempre de ônibus, eu não tenho carro também, não tenho carro de passeio, tenho não. Meu carro, meu taxi, minha moto, tudo é o ônibus. Rio Doce/CDU, ôxe, eu tenho uma amiga que mora lá em Rio Doce, e às vezes eu vou pro Janga e pego ele, paro no Bompreço, vai pro Rio Doce pego outro, rapidinho tô no Janga e de volta, converso com os motoristas e cobradores, eu sou muito... não paro, (risos) muito dinâmica. Que tem pessoas que chegam a idade mais ou menos que eu tenho e chegam meio aborrecidas, 'esse ônibus tá demorando, cobrador', pra mim não, tá tudo bem. Ás vezes eu passo direto, 'eita passei, vou retornar', aí eu retorno, muitas vezes já retornei, de tão distraída que eu fico conversando. E andar de ônibus é muito bom (...)

Muito significativos também são os depoimentos sobre a experiência do viver e pertencer à cidade (Recife ou Olinda) associados às opiniões sobre o local de moradia que, em última instância, transforma os espaços da cidade em lugar pela experiência de movimento e deslocamento proporcionada pela Linha Rio Doce/CDU. Isto se apresenta muito claramente nas seguintes falas em off de moradores de um Conjunto Habitacional em Olinda (trajeto 3 o Etapa de Rio Doce/Km 1), e também do Bairro Novo, que demonstram visões e vivências contraditórias sobre o lugar:

Morador 1: Moro há 40 anos; fui uma das primeiras a chegar. Acho um dos melhores bairros para morar.

Morador 2: Fui nascido e criado aqui; não tem para onde ir mesmo.

Morador 3: É feio, mal planejado. Quando chove é um inferno. E também não tem área de lazer nenhuma. Não tem planejamento urbano nenhum. É um buraco e quando chove incha de água. E um lugar também de muita violência.

Morador 4: É tranquilo pra mim. Graças a Deus nunca me fizeram mal. Se acontece alguma coisa, mas não é com a gente, Graças a Deus.

Morador 5: Nasci em Olinda, me criei em Olinda, tive filhos aqui em Olinda e quero morrer aqui em Olinda. Tudo aqui em Olinda, tudo natural de Olinda.

Variando entre opiniões positivas e negativas sobre a cidade e o lugar, os moradores de Olinda soam conformados com sua condição de pertencimento a esse lugar, me parecendo, contudo otimistas quanto ao futuro. Essa afirmação se comprova na resposta de um entrevistado à cineasta que solicita que ele descreva o Bairro Novo em apenas uma palavra, a qual ele 
retruca: "Desenvolvimento". Interessante notar que apenas uma das falas critica negativamente o lugar, mais especificamente o lugar de moradia, isto é, o Conjunto Habitacional, de maneira contundente e considerando o Conjunto em um contexto mais amplo que é o do mal planejamento.

Na continuidade, agora em Recife, no bairro de Campo Grande (KM 16 do trajeto), ouvimos o depoimento de um recifense usuário da Linha 920 e morador do Bairro de Campo Grande que ratifica, de forma explicita, sua "adoração" pelo lugar mesmo tendo consciência de que muito se modificou com o tempo no que toca o sentimento de insegurança na cidade:

Gosto demais; 43 anos num local, é muita coisa. Cheguei menino e hoje tô velho. Ficava aqui até dez horas da noite com a porta aberta, e não chegava ninguém. Fazia muito que não tinha ladrão, não tinha nada. Hoje quando é cinco horas da tarde, que não tem ninguém, eu fecho. Antigamente tinha mais casa, hoje tem mais comércio do que carro na avenida mesmo.

O discurso arquitetônico tem tradicionalmente representado os edifícios como objetos artísticos ou técnicos. Contudo, edifícios são também, objetos sociais já que são investidos de significado social e determinam e/ou moldam relações sociais. O filme traz o espaço do ambiente construído para o centro da discussão social e humana posta na imagem fílmica do espaço urbano de forma a produzir uma diversidade de modos de olhar, entender e interpretar os elementos culturais que envolvem os espaços e ambientes arquitetônicos. Em Rio Doce/CDU isso se dá mais efetivamente nos intervalos entre o deslocamento no percurso do ônibus pela cidade quando ex-usuários da Linha 920 são entrevistados.

No Mercado da Encruzilhada, por exemplo, duas senhoras que trabalham no Mercado dão o seguinte depoimento:

Sra 1: Essa área aqui era toda de frutas e verduras, agora tá muito diferente né? Agora tem tudo, modificou muita coisa. A área de cereais era carne, agora aí atrás passou a ser só restaurantes. Aqui tinha um paredão imenso, tiraram; cada prefeito que chega faz uma reforma, né? Mas aqui frequenta a classe de A a B. Amanhã mesmo, é a área que vai ter uma festa, vai ter os amigos do Mercado, só vem elite.

Sra 2: É, só dá elite

Sra 1: Você procura um lugar aí na frente para colocar um carro e não tem.

Cineasta/Entrevistadora: E você já tá aqui no mercado há quantos anos?

Sra 2: Eu sou a primeira, cheguei com quatro anos. Depois minha irmã chegou com quatro anos também, eu sou mais velha que ela cinco anos.

Sra 1: O dia a dia da gente é esse mesmo, é quatro e meia aqui, cinco e meia em casa. Quer dizer, a gente vive aqui e vai dormir. Minha mãe é viva e é uma das locatárias mais antigas do Mercado. Eu gosto do Mercado, pra você vê, eu digo assim: eu tô cansada, eu já me aposentei, eu só tenho um filho, mas eu fico com saudade, com pena, você acredita? Porque agora a gente tem até as filhas das freguesas de mãe e agora as filhas delas... É muito tempo no Mercado, pra você ver uma criança na gestação e vê uma criança grande fazendo compra a você, é uma satisfação, eu acho, sabe? Eu digo, eu e minha mãe, minha vida é o Mercado.

Ainda no Mercado da Encruzilhada, uma outra senhora, casada com um homem que trabalha como sapateiro no local, expressa sua ligação afetiva com o lugar conectando-o com a experiência como usuária da Linha 920: 


\begin{abstract}
Sra. do sapateiro: Eu conheci ele aqui, aqui no balcão. Eu vim aqui colocar botão de pressão, a mando de uma madrinha e tia minha. Aí vim, conheci ele, uma primeira vez, depois vim outra vez fazer outro serviço, depois nós namoramos, em 87 nós noivamos e em 88 nós casamos. O tempo que nós temos aqui..., agora, ele já estava aqui há mais tempo; que aqui ele passou do padrinho, para o tio e do tio pra ele. É um tipo assim, eras... E por coincidência, eu sou neta de sapateiro... Ah, o Rio Doce/CDU ah... Quando eu estudei em Olinda, pegava o Rio Doce no Espinheiro onde eu morava, e ia para Olinda que eu estudei na FOCCA. Eu fiz Biologia, então todos os dias eu pegava meu ônibus comum, isso já foi há 22 anos atrás.
\end{abstract}

Cineasta/Entrevistadora: Qual a lembrança que tem desse tempo do Rio Doce/CDU?

Sra do sapateiro: Muito lotado, ele só anda cheio. Somente no horário de pico. E realmente é um verdadeiro turismo, você sair de uma cidade para outra, conhecendo toda a Agamenon, chegando ao complexo Salgadinho até chegar em Olinda.

Essas falas agregam aos espaços arquitetônicos, como os Mercados da Encruzilhada (Km 17 do percurso) (e também o Mercado da Madalena mais adiante no filme) por exemplo, um significado e uma identidade enquanto lugar na proporção direta das vivências, práticas e interações sociais que acontecem no seu ambiente. Esses espaços passam a ter uma significação que advém do dia-a-dia no espaço e para e a partir do percurso, e, principalmente do afeto agregado ao espaço, consequência da memória constituída pela experiência de usuários do lugar associada à mobilidade e ao percurso de chegada e saída deste espaço representado pela Linha 920 em sua etapa do KM 17.

O filme intercala imagens captadas de fora e de dentro do ônibus durante sua trajetória de 36 $\mathrm{Km}$ pelos bairros de Olinda e Recife e depoimentos de usuários anônimos da Linha Rio Doce/CDU ou daqueles que moram e/ou trabalham no comércio das ruas por onde os ônibus da Linha 920 passam: Conjunto Habitacional 3 Etapa de Rio Doce $(\mathrm{Km} 1)$, Feira de Rio Doce (10 Etapa / Km 2), Casa Caiada (Km 7), Bairro Novo (Km 8), Carmo (Km 10), Varadouro (Km 11), Salgadinho (Km14), Recife-Campo Grande (Km 16), Encruzilhada (Km 17), Graças (Km 19), Torre (Km 19), Madalena (Km 22), Avenida Caxangá (Km 22), CDU (Cidade Universitária) (Km 29), Ponto de Retorno (CDU) (Km 36).

Há, ao longo de todo o filme, apenas uma tomada de câmera a partir do ponto de vista embaixo do ônibus no trecho em que este está partindo do Mercado da Encruzilhada. A imagem causa estranhamento por ressaltar um olhar em movimento, pouquíssimo usual, sobre o espaço urbano: detalhe da sombra do ônibus sobre o chão da rua, os meio fios das calçadas, os carros, bicicletas e motocicletas circulando em frente ao ônibus, os pés dos transeuntes atravessando a rua na frente do ônibus, tudo visto desse ponto de vista particular que, senão outra coisa, destaca a mobilidade urbana intrínseca às grandes cidades modernas.

O filme apresenta apenas duas vistas aéreas do trajeto, a saber: a do ônibus entrando na Avenida Caxangá ( $\mathrm{Km} \mathrm{22}$ ) e na Cidade Universitária (Km 29), ponto final da Linha 920. Em algum ponto na Av Caxangá (KM 22), nos é apresentado o seguinte depoimento de uma senhora proprietária de um estabelecimento comercial:

É mais de dez anos, sempre na Caxangá, entre Zumbi e Madalena, Cordeiro, mas sempre na Caxangá. Eu gosto, só fico meio sobressaltada às vezes porque às vezes é meio deserto. Mas sempre como essa é passagem de ônibus, carro, muito transeuntes, a gente tá sempre acompanhado. Aí eu tô acostumada, porque na Caxangá tudo é perto, tudo é próximo. Qualquer horário, se pegar aqui, dez minutos tá no metrô, vinte tá em Olinda, meia hora tá no Janga. Aqui tem condução para todo o lado. O ônibus ficou parecido com o Rio de Janeiro, você pega aqui na Penha e vai até a Barra da Tijuca. É que eu sou muito moderna. Eu gosto muito do moderninho, só não gosto muito da violência, mas é porque todo moderninho traz violência né? Claro, se as coisas antigamente era de um jeito e agora é de outro. Eu pegava caranguejo e era por aqui, isso aqui tinha um pedaço de mangue e 
tudo, tudo isso aqui era aqueles casarão antigo. Antigamente, minha mãe punha rede no terraço e dormia, amanhecia o dia lá, brincando, conversando. Hoje a gente não pode fazer mais isso. Mas eu sou moderna e gosto dessa modernização. Meu nome é Marlene, mas o meu apelido é "Santinha", Santinha da Caxangá, todo mundo sabe; sou eu mesma, conhecida! Muitos anos, sempre de ônibus, eu não tenho carro também, não tenho carro de passeio, tenho não. Meu carro, meu taxi, minha moto, tudo é o ônibus. Rio Doce/CDU, ôxe, eu tenho uma amiga que mora lá em Rio Doce, e às vezes eu vou pro Janga e pego ele, paro no Bompreço, vai pro Rio Doce pego outro, rapidinho tô no Janga e de volta, converso com os motoristas e cobradores, eu sou muito... não paro, (risos) muito dinâmica. Que tem pessoas que chegam à idade mais ou menos que eu tenho e chegam meio aborrecidas, 'esse ônibus tá demorando, cobrador', pra mim não, tá tudo bem. Às vezes eu passo direto, 'eita passei, vou retornar', aí eu retorno, muitas vezes já retornei, de tão distraída que eu fico conversando. E andar de ônibus é muito bom, é melhor do que ter motorista particular, tenho de adimitir, o do ônibus não, a gente fala, eles dão conselho, tem uns muito educados, tem outros groços, tem uns alegres tem uns triste, tem uns satisfeito com o salário, tem outros não, e assim vai. Ninguém tá satisfeito total mesmo. O ser humano, ele é muito difícil de se contentar totalmente, geralmente falta muita coisa. Para mim falta muito pouco para eu ser feliz; porque eu sou feliz com qualquer coisa. É noventa e nove porcento de amigos e um porcento de insatisfeitos, você não agrada a todos. Jesus que era santo, não agradou a todos, quanto mais eu né? Que sou humana e como carne e farinha.

O final do filme coincide com o final do trajeto da Linha 920, o Ponto de Retorno (CDU)(KM 36). Nessa última parada do ônibus, Adelina Pontual nos apresenta depoimentos de motoristas e cobradoras do ônibus.

Motorista 1: Eu trabalho como motorista há 13 anos. Já fui caminhoneiro, carreteiro, já trabalhei em corporativa, em várias empresas, gosto muito da minha profissão. O dia a dia é estressante, trânsito, calor e tal, mas aí a gente tem que administrar mesmo, é sobre o nosso trabalho mesmo, e a gente tem que fazer o que tem que fazer mesmo. Eu tô o que? Eu tô lidando com o público, eu tenho que ter paciência com idoso, com deficiente, com trânsito, com pedestre, com qualquer objetivo que teje pra não levar às vezes pra empresa nem trazer transtorno pra mim. Principalmente, dia de jogo, porque o pessoal de jogo, a senhora sabe né? Problema. Tem aquela galera arrastão, quebra o carro, lá vai e muitas vezes eu tava trabalhando, já arrancaram essa coisa do carro, foram lá pra cima, quebraram a janela do carro, uns vândalos, um brigando com o outro..

Motorista 2: Nesse nosso serviço nós saímos muito cedo, e às vezes chego em casa tarde, aí geralmente gera um estresse por causa disso. Vou fazer 30 anos que trabalho aqui nesse ramo já, eu acho muito gostoso mesmo, pode observar eu já trabalho rindo. ninguém em vê aqui, nunca chego aqui pra me encontrar de cara feia.

Motorista 3: O que mais cansa o motorista, na minha opinião, é o trânsito. As vias muito congestionadas, não dá condição de a gente fazer o horário com folga. Gera atraso por causa do engarrafamento que existe aí, principalmente esse percurso que é muito longo e a gente pega muito trecho engarrafado.

Cobradora: Essa linha eu acho a melhor que tem, acho a melhor que tem, gosto muito. Porque aqui é bom em tudo, sabe? Em todos os sentidos, os passageiros, às vezes você dá um troco até a mais, você tá muito, né? Eles devolvem à gente, já em outras linhas não é assim, entendeu? É educado, ajuda, se não tiver as moedas, 'deixe para lá'. É uma maravilha essa linha, é tudo de bom, pra mim é a melhor que tem. Dizem que é linha de elite, e eu gosto de coisa de elite, gosto de coisa boa, entendesse? Não anda todo o tipo de gente, entendesse? Gosto demais. Aí tu trabalha muito, é a viagem que deixa a gente quebrado né? Tem hora que não entra mais ninguém nem desce mais ninguém, mas é muito longa, Caruaru é mais perto que a CDU. 
Por esses depoimentos constatamos um "valor" agregado à experiência do viver o dia-a-dia na Linha Rio Doce/CDU diferenciado. Nessa parte do filme, somos apresentados à experiência de quem trabalha efetivamente na Linha Rio Doce/CDU. Para essas pessoas, a Linha 920 representa o "ganha pão" de todo dia; faz parte da dinâmica de produção do espaço, e da experiência afetiva que agrega o trabalho à experiência do viver diário, em movimento pela cidade, conhecendo pessoas (usuários) de todos os tipos. Após os depoimentos acima, vemos o interior do ônibus parado de onde saem os últimos passageiros; está anoitecendo; o ônibus vazio; a cena escurece e os créditos são introduzidos ao som da música "Guia de Olinda" na voz de Eddie (Erasto Vasconcelos).

\section{COSIDERAÇÕES FINAIS}

Respondendo às perguntas postas anteriormente, pode-se atestar que as imagens fílmicas evoluem em cartografias na medida em que são constructos representacionais que se articulam podendo dar origem a uma forma de mapa que efetivamente representa espacialmente, os movimentos e a experiência das coisas e das pessoas no espaço. Por isso mesmo, nosso conhecimento e entendimento dos espaços apontam para um tipo de cognição através das imagens fílmicas que serve como instrumento para a estruturação de uma geografia fílmica que dá uma dimensão mais completa da experiência nos espaços e lugares.

Nesse trabalho, consideramos que filme constrói uma cartografia móvel e perguntamos: o que ele mapeia?, e que tipo de "geografia" se materializa por meio dessa cartografia? No filme Rio Doce/CDU, são materializados os entrecruzamentos imagéticos de duas cidades - Olinda e Recife a partir de uma cartografia cinematográfica que evidentemente é construída no sentido de comprovar a necessidade primordial de estabelecer parâmetros de entendimento da relação posta entre as imagens em movimento do espaço urbano e a experiência humana de deslocamento no espaço das cidades que conhecemos. A geografia que se materializa por meio dessa cartografia é, portanto, uma geografia da representação da experiência espacial produzida, vivenciada, e certamente imaginada pela cartografia cinematográfica, que se constitui a partir de ambas existências: real e fílmica.

\section{AGRADECIMENTOS}

Agradeço ao CNPq pelo apoio financeiro, através de bolsa de Produtividade em Pesquisa, que viabilizou a produção desse artigo.

\section{REFERÊNCIAS}

COSTA, M. H. B. e V. da. Filme e Geografia: outras considerações sobre a realidade das imagens e dos lugares geográficos. Espaço \& Cultura, v. 29, p. 43-54, 2011. https://doi.org/10.12957/espacoecultura.2011.3531

DELEUZE, G.; GUATTARI, F. Mil Platôs. Rio de Janeiro: Editora 34 Letras, 1995. 1 v.

PASSOS, E.; KASTRUP, L. E. Pistas do Método da Cartografia: pesquisa-intervenção e produção de subjetividade. Porto Alegre: Editora Sulina, 2009.

SUPPIA, A. Cartografias para a Ficção Científica Mundial: cinema e literatura. São Paulo: Alameda, 2017.

SUPPIA, A. Cinema(s) Independente(s): Cartografias para um Fenômeno Audiovisual

Global. Juiz de Fora: Editora UFJF, 2013.

Recebido em: 04/10/2018

Aceito para publicação em: 07/08/2019 